\title{
Death by commissioning
}

\author{
Peter Ward, Chief Executive BDA
}

The BDJ Upfront section includes editorials, letters, news, book reviews and interviews. Please direct your correspondence to the News Editor,

Kate Quinlan at BDJNews@nature.com. Press releases or articles may be edited, and should include a colour photograph if possible.

A series of recent events lead me to conclude that NHS England (NHSE) has a master plan.

That master plan looks like a determined effort to wrest away NHS dental care from small autonomous units. That model that has been supplied by a legion of conscientious practitioners ever since the beginning of the NHS. This applies both in salaried dental service and in general practice.

In the salaried service, recent years have seen the development and growth of social enterprise companies. These have proved attractive to service commissioners because they permit the commissioning of massive amounts of dentistry via a small number of transactions. We now see huge entities responsible for the delivery of care over enormous geographic areas.

We have also seen aggressive management practices adopted in what has, traditionally, been a more benign world. By fixing contract prices of these procurements and setting expected outcomes, NHSE has absolved itself from accountability in respect of the service offering. Instead, the centre can wag its finger and invoke penalties if the service is not up to scratch.

This leaves the lucky winner of any such contract with some tough decisions. Having bid at lowest price it must then make the sums add up. With NHS terms and conditions protected (at least for the short term), the managers must try to find ways to deliver more for less in the euphemistic name of 'efficiency'. This actually translates as, restriction of training time, shortened appointments, expectations of higher throughput of complex-needs patients and the deployment of those charged with running the service to excessive chairside time. Even more sinister is what looks like a desire to replace long-serving seniors and with juniors without altering the expectations of output. Hence the rash of redundancies and performance/disciplinary proceedings redoubling the workload of our employment relations teams in this area.

'Savings' is the name of the game. That coupled with ongoing 'efficiency' signals a race to the bottom, as each year becomes more and more squeezed than the last. It can't be long before the social enterprises seek freedom from the obligations of NHS terms and conditions think about the savings to be had there!

Move then to the equivalent situation in the self-employed end of practice. As things currently stand, extant GDS contracts are enduring and infinite. But the ever lengthening list of potential contractual breaches provides more and more opportunities to take away GDS contracts and renegotiate terms. Undercutting contract prices has led to speculative competition and land-grab by the large

exercise in the South of England has chosen to use a system that requires substantial business analysis and financial standing well outside the historic experience of individual practice owners. The BDA is seeking to challenge the legitimacy of this exercise on a number of grounds.

The strongly implied preference of commissioners appears to be substantially in favour of large providers over individual units. This again brings into question the matter of NHS terms and conditions for performers. The interposition of the third party organisation offers the opportunity to disenfranchise individual dentists from their rights under conventional NHS terms and conditions. If achieved, the cost savings to NHS England could be substantial. Safe

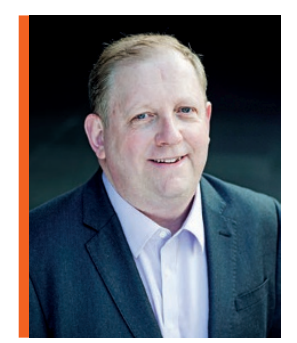

\section{'Savings is the name of the game'}

multi-site providers. Again, the attractiveness of what look like business savvy negotiators means that for local commissioners this is a preferred modus operandi. Large contracts with enormous undertakings at low prices must be attractive, particularly to commissioning managers who know nothing about what dentistry actually is.

To underline this general direction of travel it is worth looking at developments in the context of re-letting of the various expired PDS contracts. NHSE claims that it is obliged by procurement regulations to implement formal competitive tender processes determined by European precedents (although peculiarly this does not seem to apply in the devolved UK nations). The procurement of orthodontics to say that the savings will only apply if the entities can find practitioners to work under these conditions.

So, it is clear that the NHS in England stands to gain by 'going large' in all its areas of practice. But its gain is at the expense of the dentists who serve it. In essence, the wholesale dismantling of access to NHS terms and conditions provides the opportunity for savings. Proposing such a move overtly would be met with horror and outrage. Doing it stealthily and by downstream consequence may be less dramatic but the result is the same. It is not a good result for either dentists practising in England, or for patients expecting enduring, high quality care.

DOI: $10.1038 /$ sj.bdj.2017.477 